\title{
The Use of Tranexamic Acid in Percutaneous Nephrolithotomy. A Randomized Controlled Study (Local Experience)
}

\author{
Aso Omer Rashid*, Hthayyim Khalid Ahmed, Daban Mohammed Khalil Ali \\ Department of Urology, Sulaymaniyah Teaching Hospital, Sulaymaniyah, Iraq \\ Email: ^asorashed@gmail.com,drhothame67@gmail.com,daban_mahamad@yahoo.com
}

How to cite this paper: Rashid, A.O., Ahmed, H.K. and Ali, D.M.K. (2018) The Use of Tranexamic Acid in Percutaneous Nephrolithotomy. A Randomized Controlled Study (Local Experience). Open Journal of Urology, 8, 317-326. https://doi.org/10.4236/oju.2018.812035

Received: September 17, 2018 Accepted: December 10, 2018 Published: December 14, 2018

Copyright ( 92018 by authors and Scientific Research Publishing Inc. This work is licensed under the Creative Commons Attribution International License (CC BY 4.0).

http://creativecommons.org/licenses/by/4.0/

\begin{abstract}
Purpose: To evaluate the efficacy and safety of Tranexamic acid in reducing blood loss during PCNL. Materials and Methods: A total of 50 patients who underwent unilateral Percutaneous Nephrolithotomy from March 2017 to November 2017 were randomized into 2 equal groups; group (A) who received $1 \mathrm{gm}(10 \mathrm{cc})$ of tranexamic acid ampule on call to surgery and group (B) who received $(10 \mathrm{cc})$ normal saline. The Patients clinical data were collected and recorded in Microsoft Excel 2016 and analyzed using Statistical Package for the Social Science (SPSS) version 20 software program. Results: Fifty patients were included in the study: (33 males and 17 female). The mean age in group A patients was $(48.12 \pm 13.58)$ years, and in group B was $(48.88 \pm 16.17)$ with $P$ value $=0.858$. In group $A$ the number of males was 16 (64\%), and female was 9 (36\%), and in group B male was 17 (68\%) and female was $8(34 \%)$. Mean body mass index (BMI) in group A was $(28.58 \pm 4.51)$ and in group $B$ was $(26.72 \pm 3.71)$, with $P$ value $=0.119$ which is statistically not significant. The mean total blood loss in milliliters in group A was (73.80 \pm $60.1)$, while in group B it was (117.24 \pm 87.9$)$ which is statistically significant with $\mathrm{P}$-Value $=0.047$. The mean hemoglobin drop in group A was $(0.45 \pm$ $0.35 \mathrm{~g} / \mathrm{dl})$ while in group B was $(1.00 \pm 0.46 \mathrm{~g} / \mathrm{dl})$, which is statistically significant with $\mathrm{P}$ value $=0.0001$. The mean operative time was $(48.4 \pm 17)$ minute in group $\mathrm{A}$, while it was $(62.4 \pm 15)$ in group $\mathrm{B}$, with $\mathrm{P}$-Value $=0.005$, which is statistically was significant. Post-operative hematuria in group A; 20 (80\%) patients had mild hematuria, 3 (12\%) patients had moderate hematuria and 2 patients $(8 \%)$ had no hematuria. In group B; $18(72 \%)$ patients had mild hematuria, 6 (24\%) patients had moderate hematuria and one patient $(4 \%)$ had no hematuria, which is statistically not significant with $\mathrm{P}-$ Value $=0.487(\mathrm{Ta}-$ ble 2). One patient (4\%) had intra operative bleeding in group A, in group $B$ two patients $(8 \%)$ had bleeding with $\mathrm{P}$ value of 0.79 which statistically not
\end{abstract}


significant. Conclusion: Tranexamic acid is safe and effective drug in reducing blood loss and the rate of blood transfusion in percutaneous nephrolithotomy. It is associated with fewer intraoperative, postoperative complications and shorter operative time.

\section{Keywords}

Tranexamic Acid, Bleeding, Percutaneous Nephrolithotomy

\section{Introduction}

Epidemiological data on the occurrence of urolithiasis ranges between 2 and $20 \%$. Precise data on the epidemiology of a disease or disorder can only be determined if geographical position, race, age and sex, climate, nutrition and other environmental factors are also taken in consideration [1].

The high incidence and recurrence rate contribute to making the urolithiasis a serious social problem. Nowadays, urolithiasis must be considered a "disease in evolution" for several reasons, such as epidemiological changes, evolution of the methods used for diagnosis, and the treatment and prophylaxis of the population considered "at risk" of stone disease [2].

Metabolic syndrome, diabetes, hypertension and obesity are considered risk factors for urolithiasis; in contrary, stone formers are at risk of hypertension, chronic kidney disease (CKD) and end-stage renal disease (ESRD) [3].

Percutaneous nephrolithotomy (PCNL) represents a safe and efficient procedure in the surgical management of renal lithiasis. Nevertheless, surgeons need to face specific complications during and after the procedure, hemorrhage being one of the most common [4].

The percutaneous access to the kidney has grown in popularity, starting with the increasing use of percutaneous nephrolithotomy (PCNL) in the 1980s [5].

PCNL is now the standard choice for the removal of; staghorn and large $(\geq 2$ $\mathrm{cm}$ ), stones in lower pole calyces with difficult anatomy, multiple renal calculi and those resistant to ESWL, due to its minimally invasive nature and high stone-free rates reaching $\geq 90 \%[6]$.

PCNL has the advantages of higher stone clearance and cost-effectiveness when compared with other available alternatives such as flexible ureteroscopy and ESWL [7]. However, PCNL is associated with significant morbidity, among these complications bleeding is the most unpredictable, serious, and can lead to significant morbidity with transfusion rates to be from less than $1 \%$ to $10 \%$ [8].

A multi-institution study of more than 5000 patients from 96 different centers reported an overall transfusion rate of $5.7 \%$. Risk for hemorrhage was associated with stone burden and operative time [9]. Most of the bleeding that is related to PCNL can be managed with supportive treatment and blood transfusion, and only $0.8 \%$ of patients need angioembolization to control intractable bleeding [10]. Blood transfusions have potentially serious adverse effects including he- 
molytic reactions, coagulopathic complications from massive transfusion, acute lung injury, nonimmune hemolysis and transfusion related infections. [11] After any tissue trauma and surgery, the fibrinolytic system is temporarily activated by releasing tissue plasminogen activator which is a major enzyme responsible for the conversion of plasminogen to plasmin [12]. Plasmin is the main enzyme involved in fibrinolysis. Urine and urothelium contain a high concentration of plasminogen activators that facilitate the lysis of clots [13].

To reduce bleeding and the need for allogeneic blood transfusion, Antifibrinolytic drugs such as tranexamic acid has been administered in association with a variety of surgical operations [14].

Tranexamic acid is synthetic lysine analogue inhibits fibrinolysis by blocking the lysine-binding sites of plasminogen to fibrin; Fibrin is the basic framework for the formation of blood clot during hemostasis. Its half-life is approximately 80 minutes provided there is normal renal function [15], it reduces the probability of blood transfusion in elective surgery by $34 \%$ [16]. Antifibrinolytic agents have been shown to reduce blood loss in patients with normal and exaggerated fibrinolytic responses to surgery, without increasing the risk of intraoperative and postoperative complications [17]. Also, it reduces mortality in patients with trauma and substantial hemorrhage [18].

Treatment with tranexamic acid does not seem to adversely affect mortality and morbidity, in contrary, use of aprotinin which is one of Antifibrinolytic drugs [19]; associated with an increased risk of death, and recombinant activated factor VII is associated with an increased risk of arterial thromboembolic events, in addition, tranexamic acid is cheaper than other hemostatic drugs [20].

\section{Aim of the Study}

To evaluate the role and the effect of tranexamic acid in reducing the total blood loss during percutaneous nephrolithotomy and the need for blood transfusion. To assess the influence of tranexamic acid in other complications associated with percutaneous nephrolithotomy.

\section{Materials and Methods}

The research study was approved by the Ethical Committee, faculty of Medicine, Sulaymaniyah University and the Iraqi Board Council for Medical SpecializationUrology.

This is a prospective placebo-controlled randomized study from March 2017 to November 2017, at Shar teaching hospital and Zhyan private hospital in Sulaymaniyah_Iraq. Inclusion criteria were adult age above 18 years and all body-built types who had renal stones need surgery and those had failed shock wave lithotripsy. Exclusion criteria were patients with a serum creatinine greater than $1.5 \mathrm{mg} / \mathrm{dl}$, congenital renal anomalies, presence of bleeding disorders, children, sepsis and anticoagulation therapy.

A total of 50 patients were studied after they had informed consent. All pa- 
tients had full history, physical examination and blood tests including (renal function test, complete blood count, coagulopathy study, and a viral marker test), renal ultrasonography and CT urography.

Patient data were preoperatively collected and recorded in Microsoft Excel sheet 2016. The stone complexity was categorized according to the Guys grade stone and scored into 4 grades.

The patients were randomized into 2 equal groups: (group A and group B).

Patients in group (A) received $1 \mathrm{gm}(10 \mathrm{cc})$ of the tranexamic acid on call to surgery 20 minute before the procedure according to Goodman \& Gilman's the pharmacological basis of therapeutics dosing protocol; $2.5 \mathrm{mg} / \mathrm{kg}-100 \mathrm{mg} / \mathrm{kg}$ [21], While those in the group (B) had $10 \mathrm{cc}$ of normal saline injection. The operating surgeon was blinded to the randomization and the treatment protocol was similar in both groups, and all cases were done by the same surgeon.

The procedure was done under general anesthesia or spinal anesthesia according to the patients' preference and their medical condition. All patients received single dose of cefuroxime $1 \mathrm{gm}$ a prophylactic antibiotic according to the American urological association (AUA) 2017 guidelines for urological interventions. Blood was collected prior to the operation, immediate post-operative period and 24-hour post-operation. The total amount of blood was measured. The volume of irrigating fluid and volume of the fluid used during the operation were calculated and recorded.

At the end of the procedure a nephrostomy tube was kept in and a sample of drained irrigating fluid was taken to Laboratory and tested by spectrophotometer machine (ChemWell ${ }^{\odot} 2910$ Automated EIA and Chemistry Analyzer) to measure the hemoglobin content of the fluid. By knowing the volume and the $\mathrm{Hb}$ reading of the drained fluid we could calculate the estimated blood loss according to this equation

Calculated blood loss (L)

$=\frac{\mathrm{Hb} \text { concentration in irrigating fluid }(\mathrm{mg} / \mathrm{dL}) \times \text { irrigating fluid volume }(\mathrm{L})}{}$ $\mathrm{Hb}$ in blood at pre - operation $(\mathrm{g} / \mathrm{dL}) \times 103$

Operative time was recorded. Modified Clavien system was used to identifying surgical complications.

The total hemoglobin drop after the operation in every patient was calculated by recording preoperative and 24 hours postoperative hemoglobin readings.

Postoperative data were collected and recorded in Microsoft Excel sheet 2016.

Success was defined as:

1) Reduction of the amount of blood loss.

2) Complete stone clearance or the presence of residual fragments smaller than $4 \mathrm{~mm}$.

\section{Statistical Analysis}

Data were coded, entered to Microsoft Excel sheet, cleaned and analyzed using Statistical Package for the Social Science (SPSS) version 20 software program. 
Two approaches were used; descriptive and analytic, the descriptive approach included the calculation of frequencies, percentages, and means; while in the second approach comparison between means using Chi square test and independent $\mathrm{t}$-test. A ( $\mathrm{p}$-value) equal or less than 0.05 was considered statistically significant and ( $\mathrm{p}$-value) equal or less than 0.01 considered statistically highly significant.

\section{Results}

The patient demographics and clinical characteristics were nearly the same in both groups (Table 1). The total number of patients were fifty, 17 of them were females and 33 were males, the age is ranging between $20-70$ years. The mean age \pm SD of the group A was $48.12 \pm 13.58$, in the group B was $48.88 \pm 16.17$ with $P$ value $=0.858$ which is statistically not significant.

Group A male was 16 (64\%), and female was 9 (36\%). In group B male was 17 (68\%) and female was 8 (34\%). The sex distribution difference in both groups was not significant statistically with $\mathrm{P}$ value $=0.089$. BMI the mean $\pm \mathrm{SD}$ in group A was $28.58 \pm 4.51$, in control group $\mathrm{B}$ was $26.72 \pm 3.71$, with $\mathrm{P}$ value $=$ 0.119 which is statistically not significant.

In group A, medical history was positive for 11 patients; 4 (16\%) patients were diabetic, $5(20 \%)$ patients were hypertensive and $2(8 \%)$ patients had both. In group B $2(8 \%)$ patients were diabetic, 8 (32\%) were hypertensive and $3(12 \%)$ patients had both with $\mathrm{P}$ value $=0.634$. which is statistically not significant.

In group A, 5 (20\%) patients had ipsilateral open renal surgery, 2 (8\%) patients had history of PCNL, and 2 (8\%) patients had history of ESWL, in group B

Table 1. Pre-operative patient data and clinical characteristics of the sample.

\begin{tabular}{cccc}
\hline Variables & Group A & Group B & P value \\
\hline Age: mean \pm SD & $48.12 \pm 13.58$ & $48.88 \pm 16.17$ & $0.858^{*}$ \\
Sex: Male: & $16(64 \%)$ & $17(68 \%)$ & $0.089^{* *}$ \\
Female: & $9(36 \%)$ & $8(32 \%)$ & \\
BMI: kg/m mean \pm SD $^{2}$ & $28.58 \pm 4.51$ & $26.72 \pm 3.71$ & $0.119^{*}$ \\
Medical history: & & & \\
DM & $4(16 \%)$ & $2(8 \%)$ & $0.634^{* *}$ \\
HTN & $5(20 \%)$ & $8(32 \%)$ & \\
DM + HTN & $2(8 \%)$ & $3(12 \%)$ & \\
Surgical history: & & & $0.779^{* *}$ \\
Open & $5(20 \%)$ & $3(12 \%)$ & \\
PCNI & $2(8 \%)$ & $2(8 \%)$ & \\
ESWL & $2(8 \%)$ & $1(4 \%)$ & \\
Guys score: & & & \\
Grade 1 & $4(16 \%)$ & $6(24 \%)$ & \\
Grade 2 & $14(56 \%)$ & $10(40 \%)$ & \\
Grade 3 & $6(24 \%)$ & $6(24 \%)$ & \\
Grade 4 & $1(4 \%)$ & $3(12 \%)$ & \\
\hline
\end{tabular}

${ }^{\star}$ Independent $\mathrm{t}$ test. ${ }^{*}$ Chi square test. 
3 (12\%) patients had ipsilateral previous open renal surgery, 2 (8\%) patients had previous PCNL, and 1 (4\%) patient had ESWL. With $\mathrm{P}$ value $=0.779$ which is statistically not significant.

Stone complexity; in group A was Grade II in $14(56 \%)$ patients, $6(24 \%)$ grade III, 4 (16\%) grade I, and $1(4 \%)$ grade IV. In group B stone complexity were grade II in $10(40 \%)$ patients, grade III in $6(24 \%)$ patients, grade I in 6 (24\%) patients were and $3(12 \%)$ grade IV with $\mathrm{P}$ value $=0.559$ which is statistically not significant (Table 1 ).

The mean with \pm SD of total blood loss in milliliters in group A was (73.80 \pm $60.1)$, in group $B$ was $(117.24 \pm 87.9)$ with $\mathrm{P}$ value $=0.047$, which is clinically and statistically significant.

And the mean with \pm SD of hemoglobin drop in group A was $(0.45 \pm 0.35$ $\mathrm{g} / \mathrm{dl})$, in group $\mathrm{B}$ was $(1.00 \pm 0.46 \mathrm{~g} / \mathrm{dl})$, with $\mathrm{P}$ value $=0.001$ which is clinically and statistically significant.

The mean operative time in group A was ( $48.40 \pm 17.95 \mathrm{SD})$ minutes, in group $\mathrm{B}$ was $(62.40 \pm 15.48 \mathrm{SD})$ minutes with $\mathrm{P}$ value $=0.005$ which is statistically was significant.

In group A, $21(84 \%)$ were single tract and $4(16 \%)$ were multiple tract PCNL. In group B, 23 (92\%) were single tract and $2(8 \%)$ were multiple tract PCNL with $\mathrm{P}$ value $=0.384$ which is statistically not significant.

Intra operative and post-operative complication rate were lower in group A than group B. In group A bleeding was $4 \%$ (1), PCS tear; $4 \%$ (1), UTI and fever were $16 \%(4)$. In group B bleeding was $8 \%(2)$, PCS tear occurred in two patients $(8 \%)$, UTI and fever were $20 \%(5)$, but statistically (P value $=0.793)$ was not significant.

Blood transfusion rate was $4 \%$ for one patient in group A, $12 \%$ for 3 patients in group $B$ with $P$ value $=0.297$ which is statistically not significant.

The stone free rate was $100 \%$ in group A which is higher than group B (96\%), but statistically was not significant with $\mathrm{P}$ value $=0.312$.

Post-operative hematuria in group A; 20 (80\%) patients had mild hematuria, 3 (12\%) patients had moderate hematuria and 2 patients (8\%) had no hematuria. In group B; 18 (72\%) patients had mild hematuria, 6 (24\%) patients had moderate hematuria and one patient (4\%) had no hematuria, which is statistically not significant with $\mathrm{P}$ value $=0.487$ (Table 2$)$.

One patient (4\%) had intra operative bleeding in group A, in group B two patients (8\%) had bleeding with $\mathrm{P}$ value of 0.79 which statistically not significant.

Three patients had pelvic perforation, one (4\%) in group A, and two (8\%) in group B.

Nine patients had fever and UTI post operatively and stayed in hospital for 3 days, four (16\%) in group A, and five (20\%) in group B, while 41 patients were discharged from hospital after 48 hours post operatively. Nephrostomy tube removed at $1^{\text {st }}$ postoperative day in 47 patients and at 3 rd postoperative day in 3 patients. 
Table 2. Intra-operative and post-operative data.

\begin{tabular}{cccc}
\hline Variables & Group A & Group B & P value \\
\hline Blood loss (cc) mean \pm SD & $73.80 \pm 60.1$ & $117.24 \pm 87.9$ & $0.047^{*}$ \\
HB drop (g/dl) mean \pm SD & $0.45 \pm 0.35$ & $1.00 \pm 0.46$ & $0.001^{\star}$ \\
Operative time (minute) mean \pm SD & $48.40 \pm 17.95$ & $62.40 \pm 15.48$ & $0.005^{*}$ \\
Blood transfusion: & $1(4 \%)$ & $3(12 \%)$ & $0.297^{\star *}$ \\
Number of tracts: & & & \\
Single & $21(84 \%)$ & $23(92 \%)$ & $0.384^{* *}$ \\
Multiple & $4(16 \%)$ & $2(8 \%)$ & \\
Complications Bleeding & & & \\
Bleeding & $1(4 \%)$ & $2(8 \%)$ & $0.793^{\star}$ \\
PCS tear & $1(4 \%)$ & $2(8 \%)$ & \\
UTI and Fever & $4(16 \%)$ & $5(20 \%)$ & \\
\end{tabular}

${ }^{*}$ Independent $\mathrm{t}$ test, ${ }^{* *}$ Chi square test.

\section{Discussion}

There is no doubt that establishing optimal access to the renal collecting System is a key point for diminishing bleeding and improving success of the percutaneous nephrolithotomy, surgical experience is one of the potential factors that influence the risk of bleeding [22].

As the kidney is an extremely vascular organ, blood loss is a normal feature of percutaneous nephrolithotomy, necessitating transfusion in $3 \%$ to $23 \%$ of cases. Hemorrhages are usually caused by segmental arteries and controlled using conservative management methods [23].

Many clinical trials in literature are available about using Tranexamic acid perioperative for reducing the blood loss and decreasing of allogeneic blood transfusion rate in many surgical fields including; cardiac surgery, spine and orthopedic surgery, gynecological surgery, liver surgery, in all previously conducted studies TA is significantly reduced the total blood loss and the blood transfusion rate perioperatively and post operatively and no any thromboembolic events were recorded [24]. There is one prospective randomized controlled study published and it was conducted from January 2011 to June 2012 at a tertiary care medical institute in North India by Santosh Kumar and his colleagues; they used $1 \mathrm{gm}$ of TA at induction of anesthesia and followed by three $500 \mathrm{mg}$ oral doses for 24 hours post operatively for the TA group.

In the present study the mean hemoglobin drop, and the total blood loss were significantly lower in group (A) than the group (B); $(0.45 \pm 0.35 \mathrm{gm} / \mathrm{dl}$ vs $1.00 \pm$ $0.46 \mathrm{gm} / \mathrm{dl}$ with $\mathrm{P}$ value $=0.0001)$, blood loss was $(73.80 \pm 60 \mathrm{cc}$ vs $117.24 \pm 87.9$ cc with $\mathrm{P}$ value $=0.0471$ ), which is comparable to the study done by Santosh Kumar in 2012. And the blood transfusion rate was lower in group A than group B ( $4 \%$ vs $12 \%$ with $\mathrm{P}$ value $=0.297$ ).

The mean operative time also reduced significantly in group A; $(48.40 \pm 17.95$ vs $62.40 \pm 15.487$ minutes with $\mathrm{P}$ value $=0.0005)$ it is comparable with Santosh Kumar study in which the mean operative time was (48.3 vs 70.8 minutes, $\mathrm{P}$ 
value $=0.0001)$. This is can be explained that using of tranexamic acid would help to obtain better vision with shorter procedure and surgeon skill also has role in reducing operative time. [25]

The overall complication rate in our study was 38\%, it is lower than the literature results for PCNL which is reaching 83\% [26], but somewhat higher than Santosh Kumar study which was 33\%.

Collecting system tear occurred in one patient (4\%) in group A and 2 patients $(8 \%)$ in group B in our study; while in Santosh Kumar study collecting system, tear occurred in 6 patients, one (1\%) in the tranexamic acid group and 5 (5\%) in the control group).

The tear was small, and the procedure continued successfully in our study, but in Santosh Kumar study one of the tears occurred at the start of the procedure and the operation aborted.

Anuria and flank pain were developed in 2 patients with single functioning kidney in the TA group in Santosh Kumar study (because of clot obstruction of the ureter) but in the present study no one had this complication because all patients were treated by double J stent at the end of the procedure and kept in for 3 weeks, instead of using ureteral catheter which is removed 24 hours post operatively as used by them.

Postoperative fever is one of the most common complications of PCNL with the incidence rate of up to $32.7 \%$. The rate of sepsis varies between $0.97 \%-4.7 \%$ [27].

In our study fever developed in 4 (16\%) patients in group A, and 5 (20\%) patients in group B. In Santosh Kumar study fever developed in 14 (14\%) patients in the tranexamic acid group and in 15 (15\%) in the control group. Sepsis developed in 1 patient in the tranexamic acid group and in 2 in the control group. All 3 patients recovered well with appropriate management.

In the present study there was no any thromboembolic events recorded in both groups. This is like the study done by Santosh Kumar. We are unaware of any similar study performed in our area.

\section{Conclusion}

Tranexamic acid is safe and effective drug in reducing the total blood loss and the rate of blood transfusion in percutaneous nephrolithotomy. It is associated with fewer intraoperative, postoperative complications and shorter operative time.

\section{Strength and Limitations of the Study}

In this study we used accurate measurement of total blood loss by calculating irrigating fluid volume and the hemoglobin concentration of that fluid at the end of the procedure via spectrophotometer machine. And all procedures were done by the same operating surgeon.

Tranexamic acid is inexpensive and available drug in compare with other An- 
tifibrinolytic agents.

The limitation of this study is; a relatively small sample collection of patients, and there is a lack of prolonged time follow up.

\section{Conflicts of Interest}

There was no conflict of interest.

\section{References}

[1] Brändle, E., Wilbert, D., Köhrmann, K.-U. and Alken, P. (2003) European Urology, 44, 709-713.

[2] Bartoletti, R., Cai, T., Mondaini, N., Melone, F., Travaglini, F., Carini, M. and Rizzo, M. (2007) Epidemiology and Risk Factors in Urolithiasis. Urologia Internationalis, 79, 3-7.

[3] Khan, S.R., Pearle, M.S., Robertson, W.G., et al. (2016) Kidney Stones. Nature Reviews Disease Primers, 2, Article Number: 16008. https://doi.org/10.1038/nrdp.2016.8

[4] Jinga, V., Dorobat, B., Youssef, S., Radavoi, G.D., Braticevici, B., Filipoiu, F. and Balgradean, M. (2013) Transarterial Embolization of Renal Vascular Lesions after Percutaneous Nephrolithotomy. Chirurgia, 108, 521-529.

[5] Lee, J.K., Kim, B.S. and Park, Y.K. (2013) Predictive Factors for Bleeding during Percutaneous Nephrolithotomy. Korean Journal of Urology, 54, 448-453. https://doi.org/10.4111/kju.2013.54.7.448

[6] Ko, R., Soucy, F., Denstedt, J.D., et al. (2007) Percutaneous Nephrolithotomy Made Easier; a Practical Guide, Tips and Tricks. BJU International, 101, 535-539.

[7] Michel, M.S., Trojan, L. and Rassweiler, J.J. (2007) Complications in Percutaneous Nephrolithotomy. European Journal of Urology, 51, 899-906.

[8] Kukreja, R., Desai, M., et al. (2004) Factors Affecting Blood Loss During Percutaneous Nephrolithotomy: Prospective Study. Journal of Endourology, 18, 715-722. https://doi.org/10.1089/end.2004.18.715

[9] Mousavi-Bahar, S.H., Mehrabi, S. and Moslemi, M.K. (2011) Percutaneous Nephrolithotomy Complications in 671 Consecutive Patients a Single-Center Experience. The Urology Journal, 8, 271-276.

[10] El-Nahas, A.R., Shokeir, A.A., El-Assmy, A.M., Mohsen, T., Shoma, A.M., Eraky, I., El-Kenawy, M.R. and El-Kappany, H.A. (2007) Post-Percutaneous Nephrolithotomy Extensive Hemorrhage: A Study of Risk Factors. The Journal of Urology, 177, 576-579.

[11] Hendrickson, J.E. and Hillyer, C.D. (2009) Noninfectious Serious Hazards of Transfusion. Journal of Anesthia \& Analgesia, 108, 759-769. https://doi.org/10.1213/ane.0b013e3181930a6e

[12] Benon, G. and Fredin, H. (1996) Fibrinolytic Inhibition with Tranexamic Acid Reduces Blood Loss and Blood Transfusion after Knee Arthroplasty. The Journal of Bone \& Joint Surgery, 78-B, 434-440. https://doi.org/10.1302/0301-620X.78B3.0780434

[13] Kumsar, Ş., Dirim, A., Toksöz, S., et al. (2011) Tranexamic Acid Decreases Blood Loss during Transurethral Resection of the Prostate (TUR-P). Central European Journal of Urology, 64, 156-158. https://doi.org/10.5173/ceju.2011.03.art13

[14] Ducloy-Bouthors, A.-S., Jude, B., Le Goueff, F., et al. (2011) High-Dose Tranexamic 
Acid Reduces Blood Loss in Postpartum Hemorrhage. Critical Care, 15, R117. https://doi.org/10.1186/cc10143

[15] Elwatidy, S. and Jamjoom, Z., et al. (2008) Efficacy and Safety of Prophylactic Large Dose of Tranexamic Acid in Spine Surgery. Lippincott Williams \& Wilkins, 33, 2577-2580. https://doi.org/10.1097/BRS.0b013e318188b9c5

[16] Ker, K., Edwards, P., Perel, P., et al. (2012) Effect of Tranexamic Acid on Surgical Bleeding. BMJ, 344, e3054. https://doi.org/10.1136/bmj.e3054

[17] HO, K.M. and Ismail, H. (2003) Use of Intravenous Tranexamic Acid to Reduce Allogeneic Blood Transfusion in Total Hip and Knee Arthroplasty: A Meta-Analysis. Journal of Anesthesia and Intensive Care, 31, 529-537.

[18] Shakur, H., Roberts, I., Bautista, R., et al. (2010) Effects of Tranexamic Acid on Death, Vascular Occlusive Events, and Blood Transfusion in Trauma Patients with Significant Hemorrhage (CRASH-2). Lancet, 376, 23-32. https://doi.org/10.1016/S0140-6736(10)60835-5

[19] Katzung, B.G., Masters, S.B. and Trevor, A.J. (2012) Basic and Clinical Pharmacology Textbook. 12th Edition, McGraw Hill, New York, 616.

[20] Crescenti, A., Borghi, G., Bignami, E. et al. (2011) Intraoperative Use of Tranexamic Acid to Reduce Transfusion Rate in Patients Undergoing Radical Retro Pubic Prostatectomy. British Medical Journal, 343, d5701. https://doi.org/10.1136/bmj.d5701

[21] Brunton, L.L. (2011) Goodman \& Gilman's the Pharmacological Basis of Therapeutics. 12th Edition, McGraw Hill, San Diego, 849.

[22] Akman, T., Binbay, M., Sari, E., et al. (2011) Factors Affecting Bleeding during Percutaneous Nephrolithotomy. Journal of Endourology, 25, 327-333. https://doi.org/10.1089/end.2010.0302

[23] Un, S., Cakir, V., Kara, C., Turk, H., Kose, O., Balli, O. and Yilmaz, Y. (2015) Risk Factors for Hemorrhage Requiring Embolization after Percutaneous Nephrolithotomy. Canadian Urological Association Journal, 9, E594-E598.

[24] Tan, J.X., Chen, H., Liu, Q., et al. (2013) A Meta-Analysis of the Effectiveness and Safety of Using Tranexamic Acid in Primary Unilateral Total Knee Arthroplasty. Journal of Surgical Research, 184, 880-887. https://doi.org/10.1016/j.jss.2013.03.099

[25] Kumar, S., Randhawa, M.S., Ganesamoni, R., et al. (2013) Tranexamic Acid Reduces Blood Loss during Percutaneous Nephrolithotomy, Chandigarh, India. The Journal of Urology, 189, 1757-1761. https://doi.org/10.1016/j.juro.2012.10.115

[26] Tefekli, A., Karadag, M.A., Tepeler, K., et al. (2008) Classification of Percutaneous Nephrolithotomy Complications Using the Modified Clavien Grading System: Looking for a Standard. European Journal of Urology, 53, 184-190. https://doi.org/10.1016/j.eururo.2007.06.049

[27] Vorrakitpokatorn, P., Permtongchuchai, K., Raksamani, E.-O., et al. (2006) Perioperative Complications and Risk Factors of Percutaneous Nephrolithotomy. Journal of Medical Association of Thailand, 89, 826-833. 